Western University

Scholarship@Western

Biology Publications

Biology Department

$10-1-2016$

\title{
Can we predict the effects of multiple stressors on insects in a changing climate?
}

Sirpa Kaunisto

Laura V Ferguson

Brent J Sinclair

Follow this and additional works at: https://ir.lib.uwo.ca/biologypub

Part of the Biology Commons

Citation of this paper:

Kaunisto, Sirpa; Ferguson, Laura V; and Sinclair, Brent J, "Can we predict the effects of multiple stressors on insects in a changing climate?" (2016). Biology Publications. 87.

https://ir.lib.uwo.ca/biologypub/87 
1 Can we predict the effects of multiple stressors on insects in a changing climate?

2 Sirpa Kaunisto ${ }^{1,2}$, Laura V. Ferguson ${ }^{1}$ and Brent J. Sinclair ${ }^{1}$

3

4 Addresses

$5{ }^{1}$ Department of Biology, The University of Western Ontario, London, ON, N6A 5B7, Canada

$6{ }^{2}$ Department of Environmental and Biological Sciences, The University of Eastern Finland,

7 P.O. Box 111, FI-80101 Joensuu, Finland

8

9

10 Corresponding author: Sirpa Kaunisto (sirpa.kaunisto@uef.fi)

11 


\section{Abstract}

13 The responses of insects to climate change will depend on their responses to abiotic and

14 biotic stressors in combination. We surveyed the literature, and although synergistic stressor

15 interactions appear common among insects, the thin taxonomic spread of existing data means

16 that more multi-stressor studies and new approaches are needed. We need to move beyond

17 descriptions of the effects of multiple stressors to a mechanistic, predictive understanding.

18 Further, we must identify which stressor interactions, and species' responses to them, are

19 sufficiently generalizable (i.e. most or all species respond similarly to the same stressor

20 combination), and thus predictable (for new combinations of stressors, or stressors acting via

21 known mechanisms). We discuss experimental approaches that could facilitate this shift

22 towards predictive understanding. 


\section{Introduction}

25 Insects and other organisms must simultaneously respond to various, natural abiotic and

26 biotic stressors, as well as to an increasing array of novel anthropogenic environmental

27 stressors. It is often difficult to distinguish the origin of stress because natural abiotic or biotic stressors can be exacerbated by anthropogenic influences. Some of the most important human-induced or -accelerated environmental stressors include climate change, habitat fragmentation, chemical pollution and introduction of invasive species [1,2]. Different stressors will interact in various possible ways under climate change, and the responses and resistance of organisms to climate change will depend on their responses to combinations of stressors, which may or may not reflect responses to single stressors in isolation.

Multiple stressors have been studied systematically in aquatic ecosystems for non-insect organisms, especially in ecotoxicology [3-6] [ $\left.7^{\circ}\right]$, where it appears that synergistic interactions (resulting in a greater-than-expected impact) among stressors may be the norm. Here we show that multiple stressor studies on insects are still relatively rare, and discuss best practices in experimental design for multiple stressor studies that aim to characterise responses and identify underlying mechanisms, with an overall goal of predicting a priori the outcomes of interacting stressors.

\section{What do we study when we study multiple stressors?}

44 We define a 'stressor' as any environmental or biotic factor with the potential to disrupt homeostasis, performance or fitness [8]. The consequences of exposure to multiple stressors are usually separated by ecologists and ecotoxicologists into additive and non-additive (synergistic or antagonistic) effects [3,9-12]. In this review, we use the terms "synergism" and "antagonism" as a convenient way to indicate stressor interactions that result in greater or 
lesser effects than the additive sum of effects produced by the stressors acting in isolation,

50 respectively [see 5]. A range of statistical models have been used to identify non-additive effects, and, as a consequence, the strength and basis of conclusions may depend on the experimental context $[9,12,13]$. Some authors advocate using 'synergism' and 'antagonism' only to refer to effects detected by means of additive ANOVA models in a full-factorial design $[3,9,10,13,14]$. By contrast, in some disciplines, for example toxicology, the mode of actions of multiple toxicants (stressors) are always assumed to be different, leading to multiplicative (rather than additive) effects, which therefore requires appropriate statistical analysis and terminology $[9,15,16]$.

We informally surveyed the Anglophone insect literature (see supplementary material for details of the studies we identified). To narrow our criteria we focused on studies that manipulated different classes of stressors (e.g. temperature and pathogens) in full-factorial designs that allow estimation of non-additive results. A full-factorial two-stressor study would thus include four treatments; (1) neither treatment (control), (2) stressor A alone, (3) stressor B alone, and (4) both stressors, A and B, in combination. Despite the prevalence of multiple, interacting, stressors in nature, most insect studies explore effects of one stressor in isolation. At least 210 studies applying two stressors were not full-factorial in study design (e.g. lacking a stressor-free control or an individual stressor treatment). Some of those studies (e.g. those exploring interactions between temperature and pathogens and temperature and atmospheric gases) use an additional stressor to enhance the impact of a stressor of primary interest $\left[17^{\circ}\right]$, and do not use a full-factorial experimental design. Such studies cannot predict the range of non-additive responses and do not provide material for future meta-analyses on stressor interactions. We found 133 full-factorial studies (listed in Supplementary Word file), covering 24 stressor pairs (Table S1; Table S2). Fewer than ten studies included three- 
stressor combinations, and we found none including more than three stressors. The twostressor studies were spread across 12 insect orders, 51 families and 100 species (Fig. S1). This coverage of insects is still low for making far-reaching generalisations, especially when the stressor outcomes are split among many stressor pairs.

The choice of endpoints in multiple stressor studies can substantially influence the conclusions $\left[18^{\bullet}, 19\right]$. Many studies used mortality as an endpoint, for example those that explored the combined lethality of chemical and pathogen/temperature exposures. Although these studies can reveal non-additive stressor interactions, in our opinion they cannot reveal their underlying mechanisms. Many two-stressor studies used sub-lethal, fitness-related, endpoints, such as growth or fecundity (Fig. S1), which likely reflect diversion of energy to repair stress damage and re-establish homeostasis [2,20,21]. We suggest that fitness-related endpoints can shed light on underlying mechanisms of ecologically-relevant interactions among stressors.

Although the studies we included were full-factorial in design, many were unable to directly identify synergy or antagonism because of the selected statistical approach (e.g. comparing combined effects only to the univariate effects of one stressor, but not both). Thus, the results can provide only the presumption of non-additive interactions between stressors (Fig. S1; Table S2). However, studies incorporating chemical stressors (especially chemicaltemperature and chemical-pathogen interactions) more routinely used full-factorial statistical models. These studies reveal that chemicals, such as pesticides, often interact synergistically with temperature or pathogen stress. For example, in the blue-tailed damselfly Ischnura elegans, acetylcholinesterase inhibition by the pesticide chlorpyrifos was synergistically magnified when combined with heat stress $\left[1^{\bullet}\right]$. This possible predominance of synergistic 
99 interactions is consistent with observations for other animals [3,5]. We argue that the thin

100 taxonomic spread of existing data makes the insect literature currently unsuitable for formal

101 meta-analyses, but the accumulating number of primary full-factorial studies will eventually

102 be useful to identify large-scale patterns in non-additive effects among insect species and

103 stressors.

104

105 Accounting for the multiple scales of multiple stressors

106 The timing, intensity, duration, frequency and spatial distribution of stressor exposure will

107 vary among stressors and among stressor events, complicating their inclusion when

108 predicting organismal responses to multiple stressors and global change [2,22], particularly

109 when complex systems can give rise to emergent phenomena [23]. Including all possible

110 stressor combinations (and durations, sequences and intensities of stressor exposures) will

111 rapidly become intractable, but the spatio-temporal complexity of multiple stressors can be

112 reduced for experimental purposes by selecting combinations on the basis of their (co-)

113 occurrence dynamics in nature, for example, using the fractional factorial approach espoused

114 by Porter et al. (1984) [24*0].

115

116 The intensity (loosely, 'dose') of stressors can determine the outcome of interactions. This is

117 best exemplified in the concept of hormesis, wherein small doses of stress can be beneficial,

118 but large doses damaging [25]. This effect of intensity is prevalent in responses to many

119 kinds of physical, chemical or biological stressors, for example, the heat shock response is

120 induced at a threshold temperature [26], which can then substantially modify responses to

121 other stressors; however, exposure below that threshold will have minimal effect, and

122 exposure to higher temperatures may be lethal. Thus, identifying the minimum 'dose'

123 required to elicit a stress response (or an interaction - which may be a higher or lower dose) 
124 must be included in the design of experiments and choice of stressors. One approach to this

125 is to standardise the impact of stressors (the 'toxic unit approach' of ecotoxicology) to allow 126 interactions to be explored under conditions where each stressor has similar impact [cf. 27].

127 However, this standardisation may only be ecologically-relevant if the stressors in nature are 128 expected to co-occur at similar intensities.

130 The mechanisms underlying the physiological responses to stress can be tightly linked to the spatio-temporal dynamics of co-occurring stressors. For example, the physiological responses to thermal, drought or starvation stress, which often co-occur, are similar in insects [28-30].

133 By contrast, insects may experience other stressors together for the first time under global

134 change; for example, neonicotinoid insecticides and invasive pathogens [31]. Further,

135 changing climates could change the timing and severity of overlapping interacting stressors

$136\left[28^{\circ}\right]$. If a change in the sequence of two stressors does not affect the outcome and the result

137 is repeatable in one or several species, or when additional stressors are present, then the

138 responses may have underlying shared mechanisms, and thus mutually-predictable responses,

139 even if they have not previously co-occurred in nature $[32,33]$.

\section{Mechanisms underlying insect responses to multiple stressors}

142 Identifying the mechanisms underlying stressor interactions could help us to predict a priori

143 the effects of novel combinations of stressors, or to generalise the effects of multiple stressors

144 among taxa [2]. This is especially challenging when our understanding of the mechanistic

145 basis for insects' responses to even simple single stressors is incomplete. Predictable and

146 generalizable responses to multiple stressors could arise through cross-tolerance - shared

147 mechanisms of stress response that impart protection against multiple stressors once activated

148 - or through cross-talk, whereby signaling responses to the first stress also activate resistance 
149 to other stressors $\left[28^{\circ}\right]$. These underlying processes are generally conceived as adaptive,

150 leading to antagonistic effects of combined stressors, to the benefit of the insect. For

151 example, prior exposure to dehydration improves subsequent tolerance to (i.e. reduces the

152 impact of) cold or heat in the Antarctic midge Belgica antarctica, the cross-tolerance

153 facilitated by accumulation of trehalose [29]. In addition, cross-tolerance between low

154 temperature and hypoxia (or other controlled atmospheres), and their underlying

155 physiological and molecular mechanisms have been studied to some extent in insects

$156\left[17^{\bullet}, 34-36\right]$. For example, in the false codling moth Thaumatotibia leucotreta mild pre-

157 treatments with chilling and hypoxia increased resistance to low temperatures and these

158 responses were correlated with increased membrane fluidity and/or alterations in heat shock

159 protein (HSP70) [36]. The antagonistic effects of cross-tolerance or cross talk are

160 conceptually (and likely mechanistically) related to hormesis [25].

162 However, this adaptive framework based on shared responses to stressors predicts

163 antagonistic responses to multiple stressors and thus appears to be at odds with the

164 preponderance of synergistic effects of multiple stressors that we observed in our literature

165 survey (Fig. S1). Synergistic stressor interactions in insects have been most commonly

166 reported for chemical-temperature and chemical-pathogen pairs and the effects of other

167 stressor pairs have been little-studied. Thus, we lack both either the breadth of descriptive

168 data or (for many stressors) the mechanistic understanding of their mode of action necessary

169 to make predictions within this framework. However, mechanism can predict synergistic

170 responses to combined stressors, as in a scarabaeid beetle in which application of an

171 insecticide weakens the immune system, leading to a synergistic interaction when the

172 insecticide is applied in concert with a fungal pathogen [37]. These mechanism-based non-

173 additive interactions can easily yield both synergistic and antagonistic results. For example, 
174 cell membrane fluidity can determine cold tolerance in the collembolan Folsomia candida, so

175 lipophilic contaminants can either increase or reduce cold tolerance, depending on each

176 contaminants' impact on the phospholipid membrane - a property that can be predicted in

177 advance $\left[38^{\circ}\right]$. Thus, predicting the impacts of multiple stressors based on mechanism may be

178 primarily hampered by a lack of understanding of the mechanisms underlying the impact of

179 each stressor in isolation.

180

181 Can we generalize multiple stressor effects to yield predictions?

182 Currently, the insect literature is dominated by descriptive studies that characterise the

183 responses of a specific taxon to a specific combination of (usually two) stressors. When

184 designed well, these studies can identify non-additive interactions, and hint at underlying

185 mechanisms or pathways shared among stressors. However, the millions of insect species

186 and thousands of stressors mean there are trillions of potential stressor-taxon combinations,

187 so such descriptive studies fall short if we wish to account generally for multiple interacting

188 stressors in our understanding of climate change. To make a priori predictions about the

189 consequences of multiple interacting stressors, we first need to determine if the responses to

190 multiple stressors are predictable from an understanding of univariate or bivariate responses,

191 and second, determine whether such predictions are generalizable among taxa. If responses to

192 stressors are predictable, then we can draw larger conclusions about responses to novel

193 combinations of stressors (Fig. 1). Such predictability will likely arise when there are shared

194 mechanisms (or perhaps signaling pathways) underlying responses to those stressors. Thus,

195 univariate studies of single stressors, and the physiological and molecular mechanisms

196 underlying insect responses to them, are essential.

197 
198 We term responses to multiple stressors as 'generalizable' when most or all species exhibit

199 broadly similar responses to the same stressor combination, but 'idiosyncratic' if different

200 species respond differently or in a context-dependent manner (Fig. 2). The shared

201 mechanisms that underlie many stress responses [29,36,39,40], and the associations of at least

202 some stressors over evolutionary time [29] lead us to expect that at least some interactions

203 among stressors will have impacts generalizable to higher taxonomic levels. There are well-

204 established conceptual and analytical tools to assess physiological responses in a

205 phylogenetic context [41,42]. Although these have largely been applied to individual

206 stressors in insects [43-47], we expect that a phylogenetically-cogent approach, for example

207 with Drosophila $\left[4^{\circ}\right]$ will yield information on the prevalence of idiosyncratic vs.

208 generalizable responses to multiple stressors.

209

210 An alternative approach is to understand the structure of multiple stressor responses. When

211 exposed to increasing numbers of combinations of stressors, it is possible for the cumulative

212 effects to saturate or accelerate (Fig. 3). A saturation of responses would arise if there are a

213 limited number of possible interaction mechanisms among stressors, such that additional

214 stressors have limited additional impact after some threshold. By contrast, if synergistic

215 interactions combine and become increasingly synergistic with additional stress (or there are

216 emergent properties), the effect of additional stressors may continue to increase. Increasing

217 number of stressors in the green alga Chlamydomonas reinhardtii have limited impact on

218 population growth after $\mathrm{c}$. four stressors, suggesting a saturation structure to multiple

219 interacting stressors in this species [ $48^{\bullet \bullet}$, and saturation also appears to apply to toxicants

220 (the "funnel hypothesis") [49 ${ }^{\bullet \bullet}$. However, such experiments have not, to our knowledge, 
221 been conducted in insects, and even the few three-stressor studies we identified do not have

222 sufficient stressors to tease these two possible responses apart.

223

224 Conclusions

225 Although we know a lot about how insects respond to single stresses, few studies have 226 characterized responses to two stressors in combination, and studies that include three or 227 more stressors are rare. Similarly, although the mechanisms underlying responses to

228 univariate stressors have been explored, we cannot yet connect those mechanisms to the responses to stressors in combination. We suggest that using these data in phylogenetic or multiple stressor frameworks may allow determination of the predictability and generalizability of responses to multiple stressors, and that determining this will improve our ability to incorporate multiple stressors in more general models of global change.

Acknowledgements

Thanks to Vladimir Koštál, Raine Kortet, and an anonymous reviewer for suggestions that improved an earlier version of the manuscript. SK is supported by the European Union's Horizon 2020 research and innovation programme under the Marie Skłodowska-Curie grant agreement No 661122; LVF by a Postgraduate Scholarship from the Natural Sciences and Engineering Research Council of Canada.

\section{References and recommended reading}

242 Papers of particular interest, published within the period of review, have been highlighted as:

- of special interest 
246 1. Staudt A, Leidner AK, Howard J, Brauman KA, Dukes JS, Hansen LJ, Paukert C,

247 Sabo J, Solórzano LA: The added complications of climate change: Understanding

248 and managing biodiversity and ecosystems. Front. Ecol. Environ. 2013, 11:494-

249501.

250 2. Todgham AE, Stillman JH: Physiological responses to shifts in multiple environmental stressors: Relevance in a changing world. Integr. Comp. Biol. 2013, 53:539-544.

3. Crain CM, Kroeker K, Halpern BS: Interactive and cumulative effects of multiple human stressors in marine systems. Ecol. Lett. 2008, 11:1304-1315.

4. Hecky RE, Mugidde R, Ramlal PS, Talbot MR, Kling GW: Multiple stressors cause rapid ecosystem change in Lake Victoria. Freshw. Biol. 2010, 55:19-42.

5. Holmstrup M, Bindesbøl AM, Oostingh GJ, Duschl A, Scheil V, Köhler HR, Loureiro S, Soares AMVM, Ferreira ALG, Kienle C, et al.: Interactions between effects of environmental chemicals and natural stressors: A review. Sci. Total Environ. 2010, 408:3746-3762.

6. Løkke H, Ragas AMJ, Holmstrup M: Tools and perspectives for assessing chemical mixtures and multiple stressors. Toxicology 2013, 313:73-82.

263 7. Gunderson AR, Armstrong EJ, Stillman JH: Multiple stressors in a changing world:

- The need for an improved perspective on physiological responses to the dynamic marine environment. Ann. Rev. Mar. Sci. 2016, 8:357-378.

266 This review provides a physiological perspective towards understanding multiple stressor 267 interactions in marine animals.

268 8. Schulte PM: What is environmental stress? Insights from fish living in a variable environment. J. Exp. Biol. 2014, 217:23-34.

270 9. Folt CL, Chen CY, Moore MV, Burnaford J: Synergism and antagonism among 
multiple stressors. Limnol. Oceanogr. 1999, 44:864-877.

272 10. Coors A, De Meester L: Synergistic, antagonistic and additive effects of multiple stressors: Predation threat, parasitism and pesticide exposure in Daphnia magna. J. Appl. Ecol. 2008, 45:1820-1828.

11. Jorgensen SE: Ecotoxicology. Academic Press; 2010.

12. Piggott JJ, Townsend CR, Matthaei CD: Reconceptualizing synergism and antagonism among multiple stressors. Ecol. Evol. 2015, 5:1538-1547.

13. Slinker BK: The statistics of synergism. J. Mol. Cell. Cardiol. 1998, 30:723-731.

14. Greco WR, Bravo G, Parsons JC: The search for synergy: A critical review from a response surface perspective. Pharmacol. Rev. 1995, 47:331-385.

15. Greco W, Unkelbach H-D, Pöch G, Sühnel J, Kundi M, Bödeker W: Consensus on concepts and terminology for combined-action assessment: The Saariselkä Agreement. Arch. Complex Environ. Stud. 1992, 4:65-69.

16. Tang J, Wennerberg K, Aittokallio T: What is synergy? The Saariselkä agreement revisited. Front. Pharmacol. 2015, 6:1-5.

17. Boardman L, Sørensen JG, Johnson SA, Terblanche JS: Interactions between

- controlled atmospheres and low temperature tolerance: A review of biochemical mechanisms. Front. Physiol. 2011, 2:1-8. doi:10.3389/fphys.2011.00092.

This paper derives mechanism-based predictions of the interactions between cold and atmospheric composition in insects in an applied context.

291 18. Arambourou H, Stoks R: Combined effects of larval exposure to a heat wave and elegans. Chemosphere 2015, 128:148-154.

294 This paper uses a full-factorial design to explore non-additive stress responses in insects.

295 19. Janssens L, Stoks R: Synergistic effects between pesticide stress and predator cues: 
Conflicting results from life history and physiology in the damselfly Enallagma cyathigerum. Aquat. Toxicol. 2013, 132-133:92-99.

20. Sokolova IM, Frederich M, Bagwe R, Lannig G, Sukhotin AA: Energy homeostasis as an integrative tool for assessing limits of environmental stress tolerance in aquatic invertebrates. Mar. Environ. Res. 2012, 79:1-15.

21. Sokolova IM: Energy-limited tolerance to stress as a conceptual framework to integrate the effects of multiple stressors. Integr. Comp. Biol. 2013, 53:597-608.

22. Todgham AE, Schulte PM, Iwama GK: Cross-tolerance in the tidepool sculpin: The role of heat shock proteins. Physiol. Biochem. Zool. 2005, 78:133-144.

23. Woods HA, Martin LB, Ghalambor CK: Conclusions: The Central Role of the Organism in Biology. In Integrative Organismal Biology. Edited by Martin LB,

24. Porter WP, Hinsdill R, Fairbrother A, Olson LJ, Jaeger J, Yuill T, Bisgaard S, Hunter

•• WG, Nolan K: Toxicant-disease-environment interactions associated with suppression of immune system, growth, and reproduction. Science 1984, 224:1014-1017.

The little-used fractional factorial design applied in this paper is an efficient way to reduce the number of experiments required for multiple stressor studies.

25. Cutler GC: Insects, insecticides and hormesis: Evidence and considerations for study. Dose-Response 2013, 11:154-177.

26. Feder ME, Roberts SP, Bordelon AC: Molecular thermal telemetry of free-ranging adult Drosophila melanogaster. Oecologia 2000, 123:460-465.

27. Van Wijngaarden RPA, Brock TCM, Van Den Brink PJV: Threshold levels for effects of insecticides in freshwater ecosystems: A review. Ecotoxicology 2005, 
321 28. Sinclair BJ, Ferguson L, Salehipour-Shirazi G, Macmillan HA: Cross-tolerance and

322 - cross-talk in the cold: Relating low temperatures to desiccation and immune stress in insects. Integr. Comp. Biol. 2013, 53:545-556.

This review presents a cross-tolerance/cross-talk framework for understanding insect responses to interacting stressors, using low temperatures and immune and desiccation stress as case studies.

29. Benoit JB, Lopez-Martinez G, Elnitsky MA, Lee RE, Denlinger DL: Dehydrationinduced cross tolerance of Belgica antarctica larvae to cold and heat is facilitated by trehalose accumulation. Comp. Biochem. Physiol. A. 2009, 152:518-523.

30. Le Bourg É: Fasting can protect young and middle-aged Drosophila melanogaster flies against a severe cold stress. Biogerontology 2013, 14:513-529.

31. Doublet V, Labarussias M, de Miranda JR, Moritz RFA, Paxton RJ: Bees under stress: Sublethal doses of a neonicotinoid pesticide and pathogens interact to elevate honey bee mortality across the life cycle. Environ. Microbiol. 2015, 17:969-

32. Baldwin WF: Combined effects of heat and radiation on the frequency of eye colour mutations and malformations in Dahlbominus. Mutat. Res. 1975, 27:143-

33. Bitsadze N, Jaronski S, Khasdan V, Abashidze E, Abashidze M, Latchininsky A, Samadashvili D, Sokhadze I, Rippa M, Ishaaya I, et al.: Joint action of Beauveria bassiana and the insect growth regulators diflubenzuron and novaluron, on the migratory locust, Locusta migratoria. J. Pest Sci. 2013, 86:293-300.

34. Deutsch C, Ferrel A, Seibel B, Pörtner H-O, Huey RB: Climate change tightens a metabolic constraint on marine habitats. Science 2015, 348:1132-1135.

35. Verberk WCEP, Overgaard J, Ern R, Bayley M, Wang T, Boardman L, Terblanche JS: 
Does oxygen limit thermal tolerance in arthropods? A critical review of current evidence. Comp. Biochem. Physiol. A. 2016, 192:64-78.

36. Boardman L, Sørensen JG, Terblanche JS: Physiological and molecular mechanisms associated with cross tolerance between hypoxia and low temperature in Thaumatotibia leucotreta. J. Insect Physiol. 2015, 82:75-84.

37. Hiromori H, Nishigaki J: Factor analysis of synergistic effect between the entomopathogenic fungus Metarhizium anisopliae and synthetic insecticides. Appl.

38. Holmstrup M, Bouvrais H, Westh P, Wang C, Slotsbo S, Waagner D, Enggrob K,

- Ipsen JH: Lipophilic contaminants influence cold tolerance of invertebrates through changes in cell membrane fluidity. Environ. Sci. Technol. 2014, 48:97979803.

This paper is an excellent example of taking a mechanistic approach to stressor interactions in soil animals.

39. Levis NA, Yi S-X, Lee RE: Mild desiccation rapidly increases freeze tolerance of the goldenrod gall fly, Eurosta solidaginis: evidence for drought-induced rapid

40. Terhzaz S, Teets NM, Cabrero P, Henderson L, Ritchie MG, Nachman RJ, Dow JAT,

41. van Kleunen M, Dawson W, Bossdorf O, Fischer M: The more the merrier: Multi-

42. Garland T, Bennett AF, Rezende EL: Phylogenetic approaches in comparative physiology. J. Exp. Biol. 2005, 208:3015-3035. 
tolerance in Drosophila larvae. Physiol. Biochem. Zool. 2011, 84:43-53.

372 44. Nyamukondiwa C, Terblanche JS, Marshall KE, Sinclair BJ: Basal cold but not heat tolerance constrains plasticity among Drosophila species (Diptera: Drosophilidae). J. Evol. Biol. 2011, 24:1927-1938.

45. Mitchell KA, Sinclair BJ, Terblanche JS: Ontogenetic variation in cold tolerance plasticity in Drosophila: Is the Bogert effect bogus? Naturwissenschaften 2013,

46. MacMillan HA, Ferguson L V, Nicolai A, Donini A, Staples JF, Sinclair BJ: Parallel ionoregulatory adjustments underlie phenotypic plasticity and evolution of Drosophila cold tolerance. J. Exp. Biol. 2015, 218:423-432.

47. Kellermann V, Loeschcke V, Hoffmann AA, Kristensen TN, Fløjgaard C, David JR,

- Svenning JC, Overgaard J: Phylogenetic constraints in key functional traits behind species' climate niches: Patterns of desiccation and cold resistance across 95 Drosophila species. Evolution 2012, 66:3377-3389.

This paper is an outstanding example of understanding univariate stress responses in the phylogenetic framework we recommend for examining multiple stressors.

387 48. Brennan G, Collins S: Growth responses of a green alga to multiple environmental •• drivers. Nat. Clim. Chang. 2015, 5:892-897.

This landmark paper describes the architecture of responses to large numbers of combined

390 stressors in marine algae. We believe that this approach could be readily applied in insects.

391 49. Warne MSJ, Hawker DW: The number of components in a mixture determines 


\section{$400 \quad$ Figure 1}

401 Shared response mechanisms can hypothetically be used to predict responses to novel stressor

402 combinations. Stressor pairs $\mathrm{P}+\mathrm{Q}$ and $\mathrm{P}+\mathrm{R}$ share same mechanism $(\mathrm{X})$ resulting in a shared 403 response or outcome $(\mathrm{O} 1)$. In this example, the new stressor pair $\mathrm{T}+\mathrm{S}$ also share response 404 mechanism X, so we predict the $\mathrm{O} 1$-response.

405

406 Figure 2

407 Responses to interacting stressors can be generalizable or idiosyncratic. This may be evident 408 when responses are compared across a phylogeny (A), where a strong phylogenetic constraint 409 can imply a generalizable response. We speculate that generalizable responses arise when 410 mechanisms are shared (Figure 1), but idiosyncratic, if the same mechanisms yield different 411 responses (B), or if the mechanisms themselves are context-dependent (C).

412

\section{Figure 3}

414 When exposed to increasing numbers of combinations of stressors, it is possible for the 415 cumulative effects to saturate (A) because many stressors use same mechanism, or accelerate 416 if synergistic interactions combine and become increasingly synergistic with additional 417 stressors (B). In the case of saturation the number of tractable multi-stressor experiments 418 could be reduced. In the negative scenario, increasing number of stressors result in 419 acceleration of stress responses with high diversity of mechanisms and accumulation of 420 synergism making the number of required experiments intractable. 
Stressor pairs

$\mathrm{P}+\mathrm{Q}$

$\mathrm{P}+\mathrm{R}$

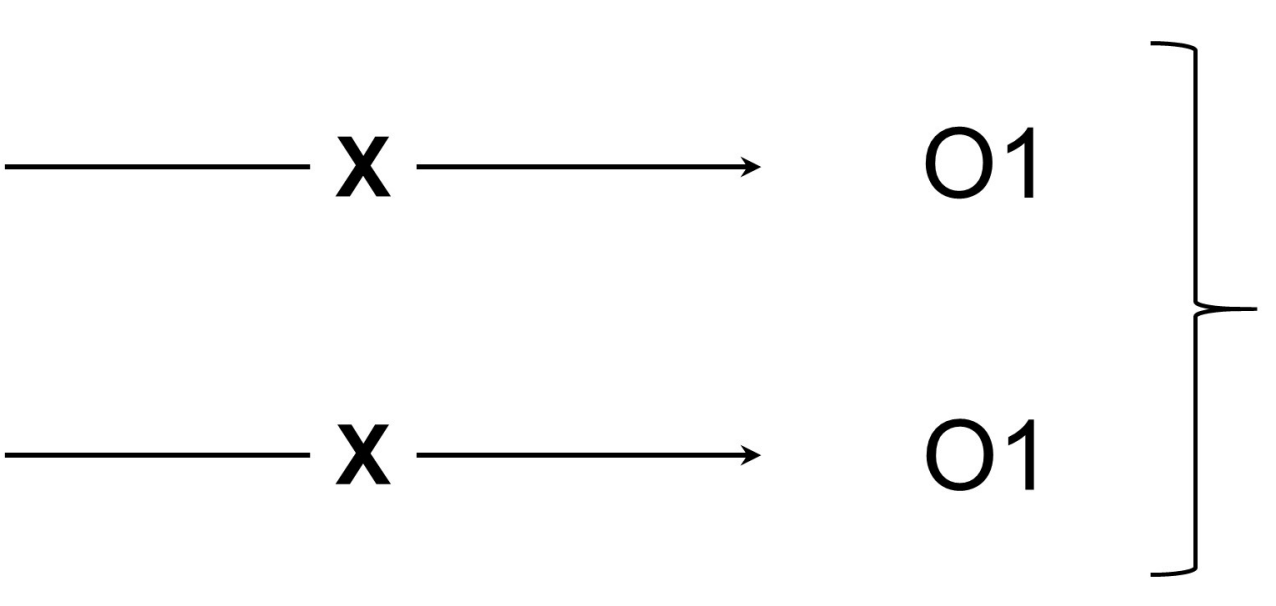

New stressors

$\widehat{T}+\mathrm{s}$
X

X

O1

Mechanism

Mechanism

Outcome (0)

Predicted outcome (O)

01
Shared mechanisms $=$ predictable responses

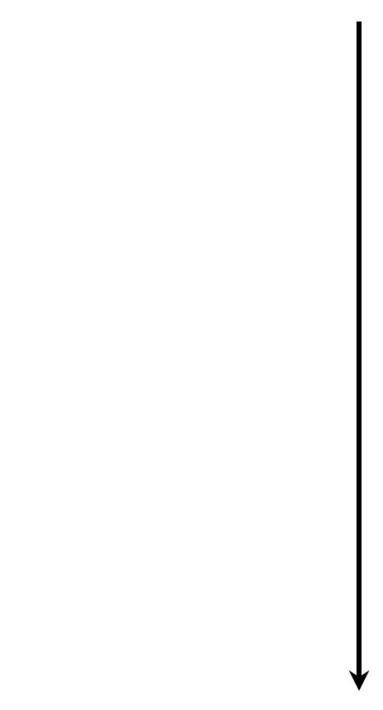

Same mechanism $(X) \rightarrow$ predictable response 
A)

Idiosyncratic

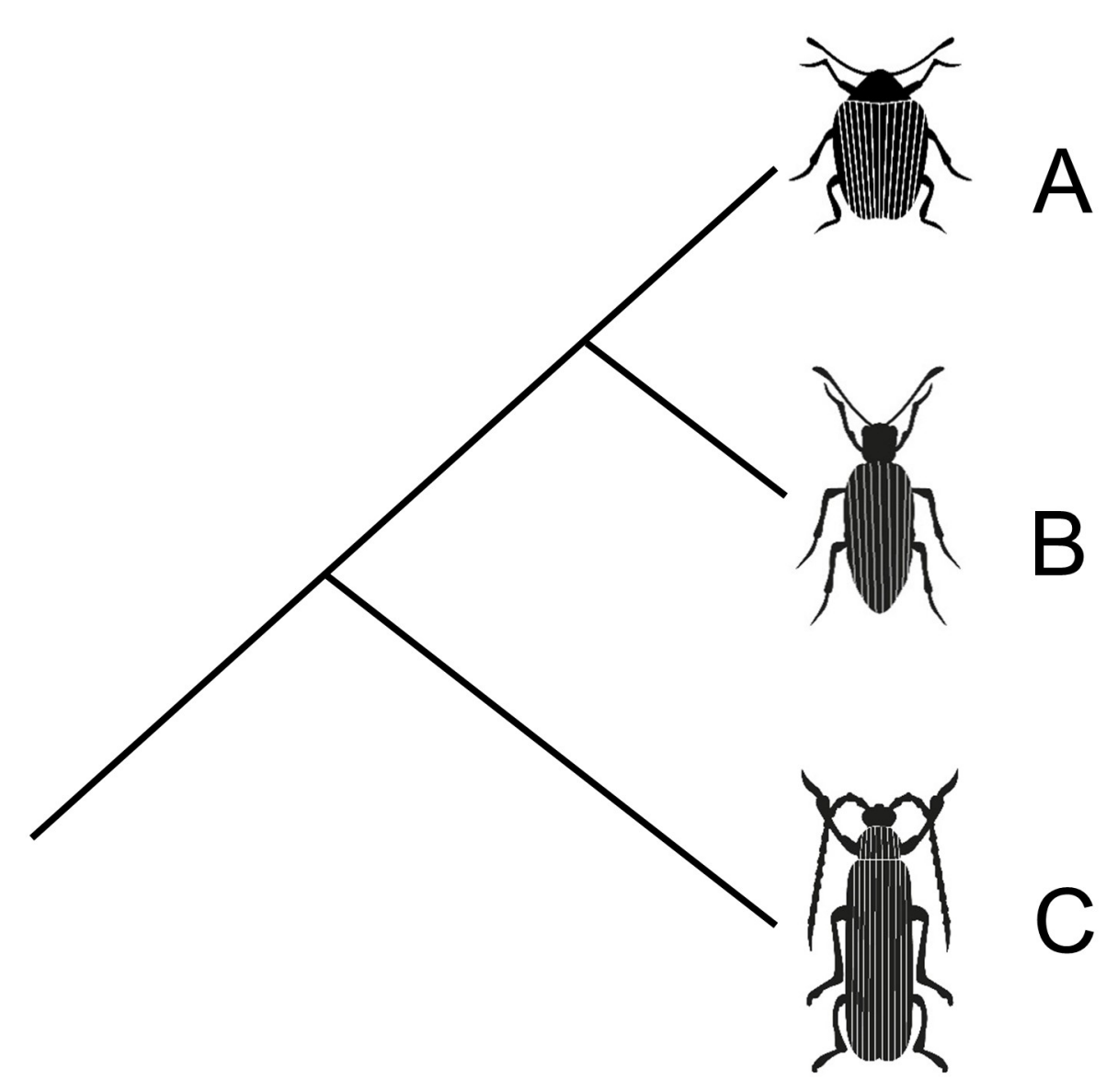

B )

Mechanism Outcome (0)
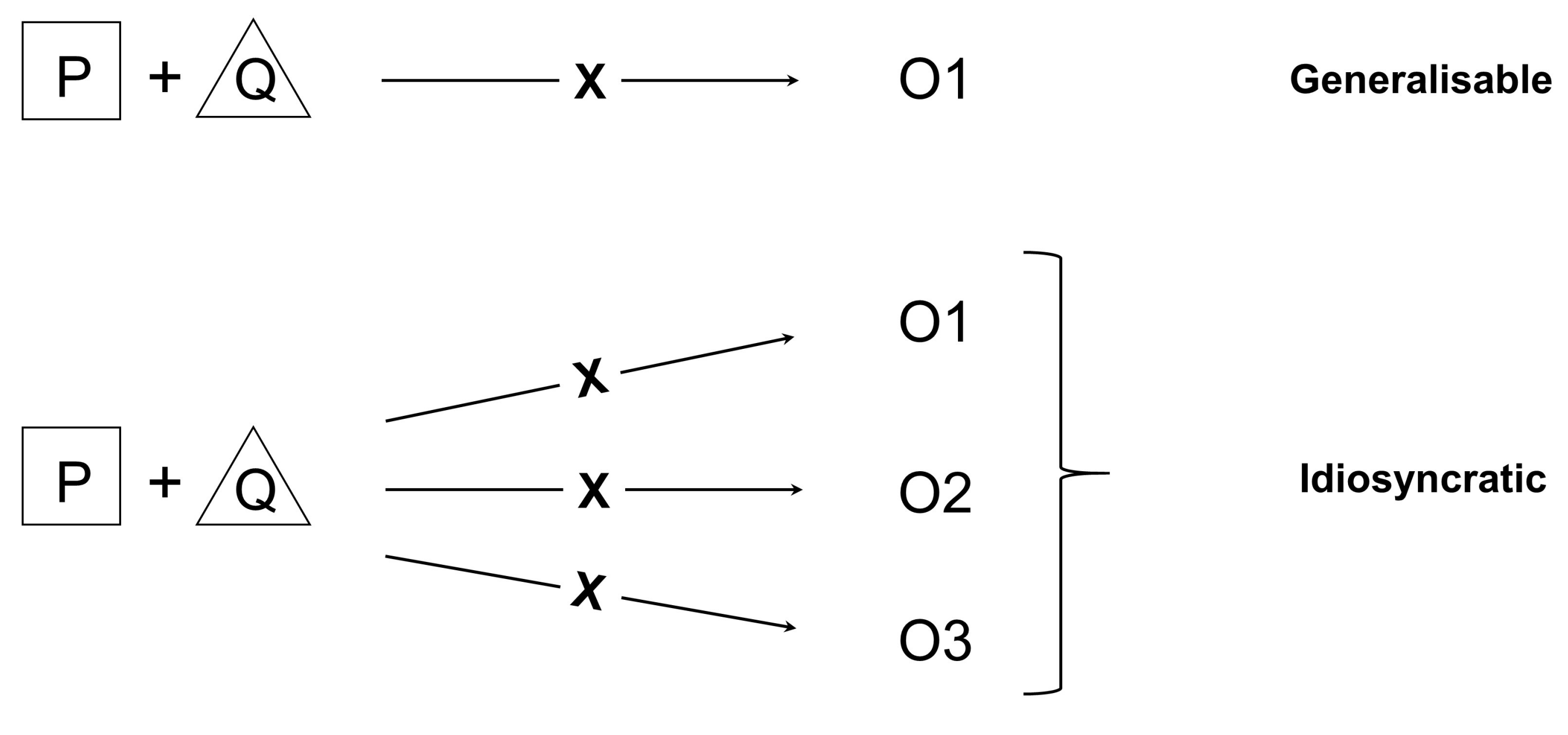

Idiosyncratic

C)

Stressor pair Mechanism Outcome (0)

$\mathrm{P}+\hat{\mathrm{Q}} \mathrm{x} \longrightarrow \mathrm{O} 1 \quad$ Generalisable

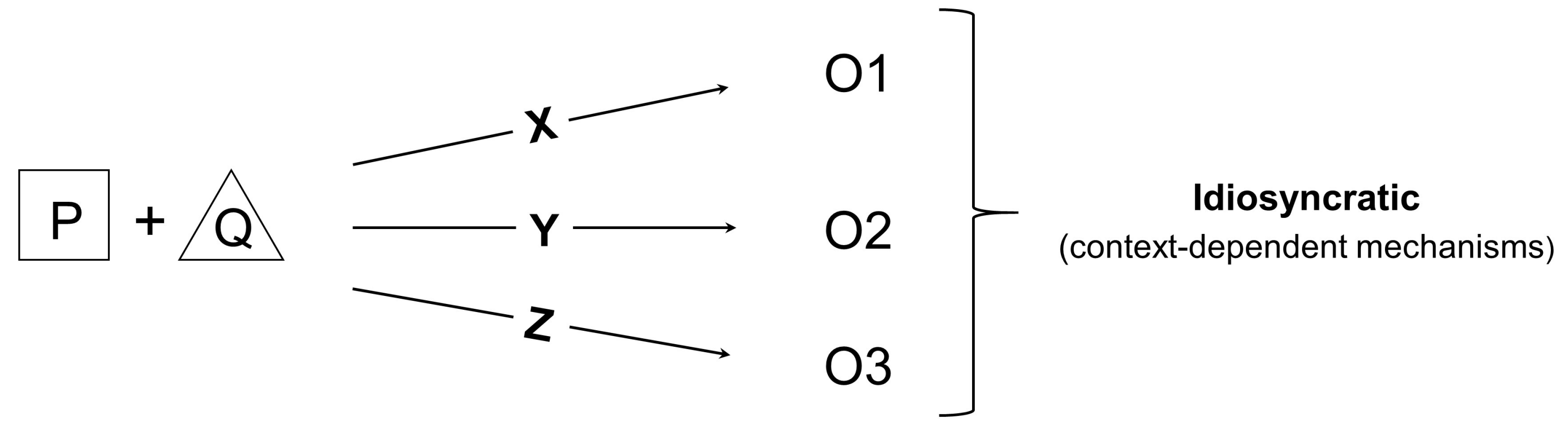


A)

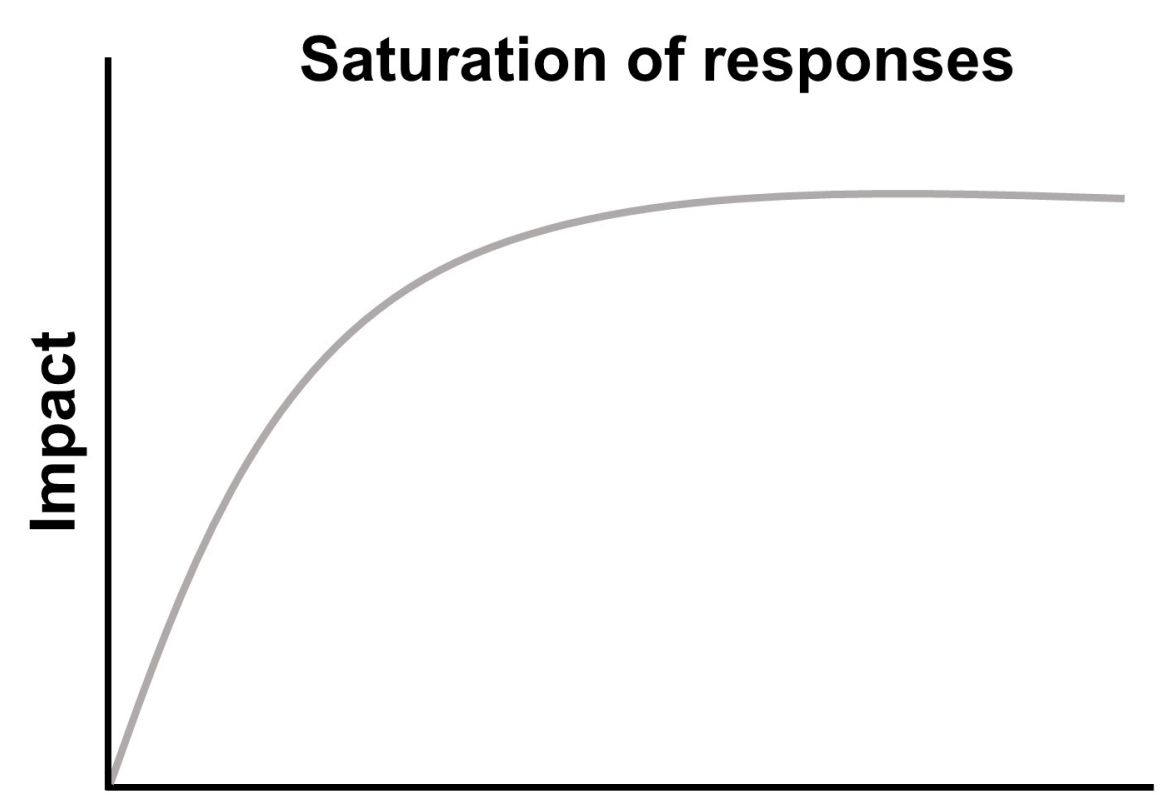

Number of stressors
B )

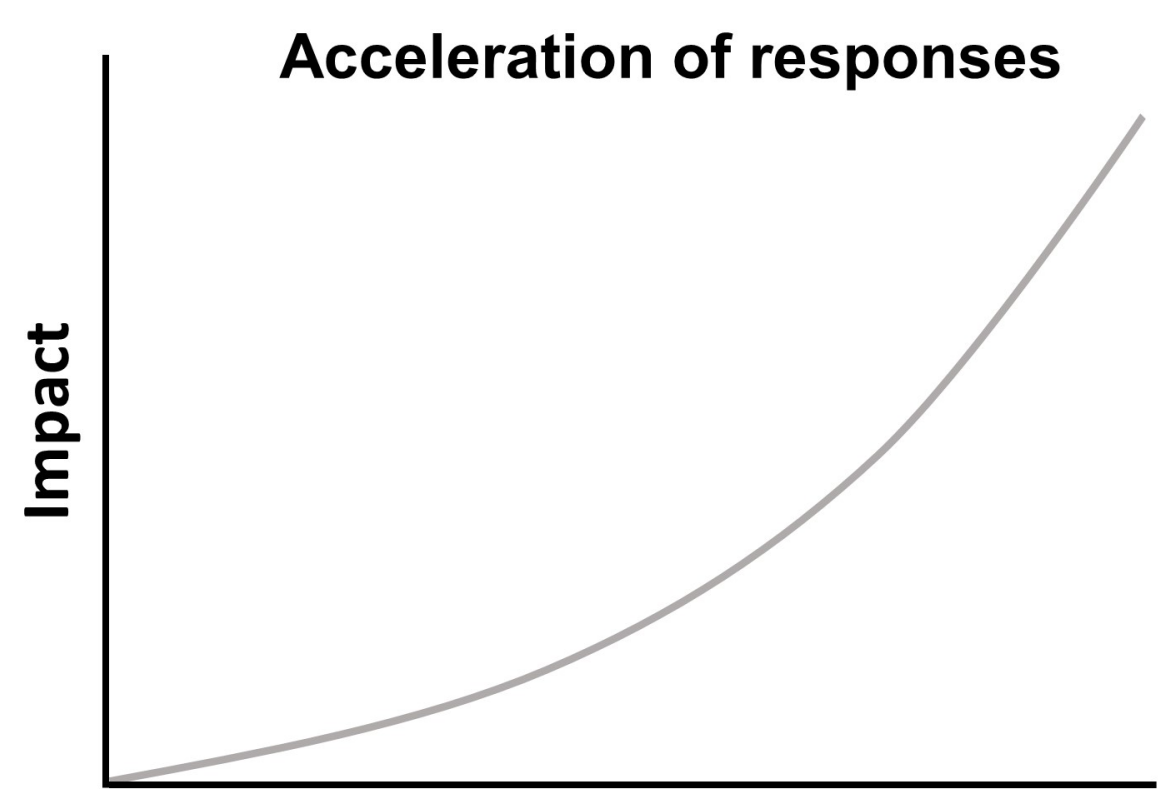

Number of stressors 